\title{
TITLE PAGE
}

\section{Airway management, procedural data, and mortality records of patients undergoing surgery for mucormycosis associated with coronavirus disease (COVID-19)}

\section{Author Names:}

Prashant Sirohiya ${ }^{1}$, Saurabh Vig${ }^{1}$, Tanmay Mathur ${ }^{1}$, Jitendra Kumar Meena ${ }^{2}$, Smriti Panda ${ }^{3}$, Gitartha Goswami ${ }^{1}$, Raghav Gupta ${ }^{1}$, Abhilash konkimalla ${ }^{3}$, Dheeraj Kondamudi ${ }^{3}$, Nishkarsh Gupta $^{1}$, Brajesh Kumar Ratre ${ }^{1}$, Ram Singh ${ }^{1}$, Balbir Kumar ${ }^{1}$, Anuja Pandit ${ }^{1}$, Kapil Sikka ${ }^{3}$, Alok Thakar ${ }^{3}$, Sushma Bhatnagar ${ }^{1}$

1 Department of Onco-anaesthesia and Palliative Medicine, All India Institute of Medical Sciences, New Delhi

2 Department of Preventive Oncology, All India Institute of Medical Sciences, New Delhi

3 Department of Otorhinolaryngology and Head and Neck Surgery, All India Institute of Medical Sciences, New Delhi

\section{\#Corresponding Author}

Prof Sushma Bhatnagar

Head, Department of Onco-anaesthesia and Palliative medicine

All India Institute of Medical Sciences, New Delhi

sushmabhatnagar1@gmail.com

Mobile: - +91-9811326453

\section{Declarations}

Ethics approval: The study was approved from Institutional Ethics Committee of All India Institute of Medical Sciences, New Delhi (IEC-450/02.07.2021)

Availability of data and materials: Available on Request

Conflict of interests: The authors have no conflict of interest.

Funding: The authors received no funding for this project. 
Prior publication: The article has been hosted on the preprint server MedRxiv (https://doi.org/10.1101/2021.09.06.21263168)

\section{Support: Nil}

\section{Conflicts of interest: Nil}

\section{Permissions: Nil}

\section{Author's Contributions}

- Prashant Sirohiya was involved in the conceptualization of the study, study design, patient care, data collection, statistical analysis, and in writing the first draft of the manuscript and agrees to be the guarantor of the manuscript taking responsibility for the integrity of the work as a whole, from inception to published article

- Saurabh Vig and Jitendra Meena were involved in the conceptualization of the study, study design, patient care, data collection, statistical analysis, and critique of the manuscript

- Tanmay Mathur, Gitartha Goswami, and Raghav Gupta were involved in the conceptualization of the study, study design, patient care, and in writing the first draft of the manuscript

- Smriti Panda, Abhilash Konkimalla, and Dheeraj Kondamudi was involved in the conceptualization of the study, study design, patient care, and in the critique of the manuscript

- Nishkarsh Gupta, Brajesh Kumar Ratre, Ram Singh, Balbir Kumar, Anuja Pandit, were involved in study design, patient care, and in the critique of the manuscript

- Kapil Sikka and Alok Thakar were involved in the conceptualization of the study and final critique and review of the manuscript

- Sushma Bhatnagar was involved in the conceptualization of the study, convening of the working group, study design, patient care, in final critique and review of the manuscript and agrees to be the guarantor of the manuscript taking responsibility for the integrity of the work as a whole, from inception to published article

Word count: 
medRxiv preprint doi: https://doi.org/10.1101/2021.09.06.21263168; this version posted November 1, 2021. The copyright holder for this preprint (which was not certified by peer review) is the author/funder, who has granted medRxiv a license to display the preprint in perpetuity.

All rights reserved. No reuse allowed without permission.

- $\quad$ Summary

- $\quad$ Text (Excluding References \& Abbreviations)

Number of tables

Number of references
: $\quad 248$

: 1999

: 3

: $\quad 23$ 


\section{Airway management, procedural data, and mortality records of patients undergoing surgery for mucormycosis associated with coronavirus disease (COVID-19)}

\section{Abstract \\ Purpose}

Although unexpected airway difficulties are reported in patients with mucormycosis, the literature on airway management in patients with mucormycosis associated with Coronavirus disease is sparse.

\section{Methods}

In this retrospective case record review of 57 patients who underwent surgery for mucormycosis associated with coronavirus disease, we aimed to evaluate the demographics, airway management, procedural data, and mortality records.

\section{Results}

Forty-one (71.9\%) patients had a diagnosis of sino-nasal mucormycosis, fourteen $(24.6 \%)$ patients had a diagnosis of rhino-orbital mucormycosis, and 2 (3.5\%) patients had a diagnosis of palatal mucormycosis. A total of $44(77.2 \%)$ patients had co-morbidities. The most common co-morbidities were diabetes mellitus in $42(73.6 \%)$ patients, followed by hypertension in $21(36.8 \%)$ patients, and acute kidney injury in $14(28.1 \%)$ patients. We used the intubation difficulty scale score to assess intubating conditions. Intubation was easy to slightly difficult in $53(92.9 \%)$ patients. In our study, mortality occurred in 7 (12.3\%) patients. The median (range) mortality time was 60 (27-74) days. The median (range) time to hospital discharge was 53.5 (10-85) days. The median [interquartile range] age of discharged versus expired patients was $47.5[41,57.5]$ versus $64[47,70]$ years $(P=0.04)$, and median (interquartile range) D-dimer levels in discharged versus expired patients was 364 [213, 638] versus $2448[408,3301] \mathrm{ng} / \mathrm{mL}(\mathrm{P}=0.03)$.

\section{Conclusion}

In patients undergoing surgery for mucormycosis associated with the coronavirus disease, airway management was easy to slightly difficult in most patients. Perioperative complications can be minimized by taking timely and precautionary measures.

Keywords: Airway, COVID-19, Mucormycosis, Coronavirus disease. Intubation difficulty scale, Mortality 


\section{Introduction}

Mucormycosis is an acute-onset, aggressive, and rapidly progressive angioinvasive infection caused by saprophytic fungi of the order Mucorales. The most common underlying risk factor associated with mucormycosis is uncontrolled diabetes mellitus. Hematopoietic stem cell and solid organ transplants, corticosteroid therapy, neutropenia, or drug-induced immunosuppression are other identifiable risk factors.[1,2]

There was a sudden increase in cases of mucormycosis in the second wave of Coronavirus disease (COVID-19) in India.[3,4] The management plan of these cases included surgical debridement, systemic antifungal therapy, sugar control, and management of systemic adverse effects related to the antifungal therapy.[5] Diabetes mellitus has been recognized as the most common coexisting concomitant disease. Attention must be given to control blood glucose.[6] In addition, airway management in these patients may be difficult due to the aggressive nature of the disease. The oropharyngeal region may be involved by fungi and edema in the supraglottic region may cause difficult endotracheal intubation and difficult ventilation.[7-9] These patients are receiving injections of amphotericin B which may have significant adverse effects such as nephrotoxicity, hypokalemia, hypomagnesemia, fever, tremor, dyspnea, and hypotension.[10] Apart from this, COVID-19 itself has harmful effects on various organs of the body. Many of these patients require surgical debridement of the involved tissues and anesthesiologists are involved in the multidisciplinary perioperative management of mucormycosis associated with COVID-19.[9]

The mortality rate for mucormycosis associated with COVID-19 is less known but the overall mortality rate for mucormycosis is $54 \%$.[11] There is a risk of involvement of vital structures such as the brain and eye, so surgical debridement should be planned on an urgent basis as a delay can worsen the prognosis. There may be less time to optimize patient comorbidities, making perioperative management challenging. Since all patients in our study are positive for COVID-19, problems caused by wearing personal protective equipment, limited staffing, and supplies are additional difficulties in managing these patients.[12]

Although unexpected airway difficulties are reported in patients with mucormycosis, the literature on airway assessment and management in patients with mucormycosis associated with COVID-19 is sparse. In this study, we aimed to evaluate demographics, airway assessment and management, procedural data, and mortality records in patients undergoing surgery for mucormycosis associated with COVID-19. 


\section{Methods}

Study Design

A retrospective review of the medical records of patients who underwent surgery for mucormycosis associated with COVID-19 at the National Cancer Institute (Jhajjar) between 6 May 2021 and 15 June 2021 was performed.[4] Patients with incomplete medical records were excluded from the study.

\section{Study Setting and Population}

The study included 57 COVID-19 positive patients who underwent surgery for mucormycosis under general anesthesia. The study was approved by the Institute Ethics Committee (IEC-450/02.07.2021) of the All India Institute of Medical Sciences, New Delhi.

\section{Study Objectives}

The primary objective was to describe airway assessment and management and the secondary objective of the study was to describe demographics, procedural data, and mortality records.

\section{Study Protocol}

Preoperative data included demographic characteristics, disease type, patient comorbidities, smoking and alcohol status, laboratory investigations, vital parameters, and airway assessment. The airway was assessed under the following headings: mouth opening, presence of loose teeth, dentures or bucktooth, whether the patient was edentulous, Mallampatti scoring, neck movements, thyromental distance, presence of short neck, presence of receding chin, and post-surgical changes.[13,14] All the surgeries were performed under general anesthesia. All anesthesiologists involved in the procedure had at least 3 years of clinical experience. As a protocol, if mouth opening was adequate, we used a conventional C-MAC video laryngoscope for endotracheal intubation. We calculated the Intubation difficulty score (IDS) to assess intubating conditions.[15,16] This includes the following parameters: number of intubation attempts, number of operators, number of alternative techniques, CormackLehane grade, whether lifting pressure is necessary, whether or not laryngeal pressure is applied, and vocal cord mobility. IDS value $=0$ represents easy intubation, a score of $>0$ and $\leq 5$ represents slightly difficult intubation, and a score $>5$ represents moderate to major difficult intubation. The time required for intubation and the percentage of glottic opening (POGO) were also noted.[17] Data related to the procedure were also recorded in terms of 
nasogastric tube insertion, invasive monitoring, central venous catheter insertion, blood loss, urine output, etc.

The duration of anesthesia was defined as the time between induction of anesthesia and transfer of the patient to the post-anesthesia care unit (PACU) or ICU. Patients who required postoperative mechanical ventilation or who had undergone extensive surgery were transferred directly from the operation theater to the ICU. Patient data regarding length of hospital stay and mortality were obtained from hospital records. Duration of hospital stay was defined as the number of days between the date of hospitalization to the date of discharge/death.

\section{Statistical Analysis}

Data related to the variables selected in the study were extracted from the records and entered into MS Excel software version 16.0 (Microsoft Inc.) for summative analysis. Data were summarized using the median with the interquartile range [25th, 75th] or median (range) for continuous variables and numbers and proportions (\%) for categorical variables. Statistical review of the data was performed using IBM SPSS version 24 (SPSS Inc., Chicago IL, USA). A P-value of less than 0.05 was considered statistically significant.

\section{Results}

The demographic and clinical characteristics of the patients are presented in Table 1 . The 57 patients consisted mostly of men $35(61.4 \%)$ with a mean age of $49(26,78)$ years. The median body weight and height were $64(46,82) \mathrm{kg}$ and $1.67(1.45-1.81)$ meters. Most patients had American Society of Anesthesiologists (ASA) scores II (40.4\%) and III (40.4\%).[18] Forty-one (71.9\%) patients had sino-nasal mucormycosis, fourteen $(24.6 \%)$ had rhino-orbital mucormycosis (out of which 2 patients had a cerebral extension), and 2 patients (3.5\%) was diagnosed with palatal mucormycosis. Total 44 (77.2 \%) patients had comorbidities. The most common co-morbidity was Diabetes Mellitus 42 (73.6\%), followed by hypertension $21(36.8 \%)$ and Acute kidney injury $14(28.1 \%)$.

Airway assessment and management, and procedural data parameters are presented in Table 2. In all 57 patients, mask ventilation was without difficulty. Fifty-six (98.3\%) patients underwent oral endotracheal intubation using a conventional C-MAC laryngoscope. One patient had restricted mouth opening ( $<1$ finger), for which we performed nasotracheal intubation using a fiberoptic bronchoscope. The first pass intubation success rate was $92.9 \%$. 
We calculated the Intubation difficulty score to assess intubating conditions and we found a score of 0 (Easy) in 11 patients, a score of $>0$ to $\leq 5$ (slightly difficulty) in 42 patients, and a score $>5$ (moderate to major difficulty) in 3 patients.

The median percentage of glottic opening (POGO) score was $80(20,100) \%$ and the time required for intubation was $15(10,180)$ seconds. All patients received crystalloids while 2 patients additionally received blood transfusions. We performed peripherally inserted central catheterization in $47(82.5 \%)$ patients and internal jugular vein cannulation in 7 (12.3\%) patients. In 3 patients, internal jugular venous cannulation was performed before their surgery. Nasogastric tube insertion was performed in 19 (33.3\%) and Foley catheterization was performed in $19(33.3 \%)$ patients. The median blood loss was $150(50,500) \mathrm{ml}$ and urine output was $250(200,300) \mathrm{ml}$. Preoperative investigations are listed in Table 3. The median duration of anesthesia was $150(90,270)$ min. Forty-one $(71.9 \%)$ patients were extubated after surgery in the operation theatre. Sixteen $(28.1 \%)$ patients were transferred to the intensive care unit for postoperative elective mechanical ventilation. The reason for postoperative elective mechanical ventilation was extensive surgery in 14 patients and inadequate reversal from anesthesia in 2 patients. Eight out of 16 patients were extubated on postoperative day 0 , 6 patients on postoperative day 1 , and 2 patients on day 2. After extubation, a high flow nasal cannula (HFNC) is required in one patient for 10 days. The patient was later weaned from it.

In our study, mortality occurred in $7(12.3 \%)$ patients. The median (range) mortality time was 60 (27-74) days. The median (range) time to hospital discharge was 53.5 (10-85) days. We did a comparative analysis between discharged patients and expired patients. The median [interquartile range] age of discharged versus expired patients was 47.5 [41,57.5] versus 64 $[47,70]$ years $(\mathrm{P}=0.04)$, and median (interquartile range) $\mathrm{D}$-dimer levels in discharged versus expired patients was $364[213,638]$ versus $2448[408,3301] \mathrm{ng} / \mathrm{mL}(\mathrm{P}=0.03)$.

\section{Discussion}

Surgical debridement of mucormycosis is an invasive procedure and airway management of patients can be challenging. Involvement of the oropharyngeal region by fungus and supraglottic edema can lead to difficulties with mask ventilation and endotracheal intubation.[8] In one study, 3 patients had fungal debris in the oropharyngeal region, and in one of these patients, due to supraglottic edema, a video laryngoscope was used for endotracheal intubation.[19] In our study, mask ventilation was not difficult in any of our patients. First pass intubation success was $92.9 \%$. Two attempts were made in 4 (7.0\%) 
patients. Two patients required an intubation stylet for their endotracheal intubation and two patients had difficulty guiding the endotracheal tube through the glottis on the first attempt but the second attempt was successful. In one patient, restricted mouth opening was present, therefore, fiberoptic bronchoscope-guided intubation was performed. Rest all patients are intubated by C-MAC video laryngoscope as per departmental COVID-19 protocol. We did not find any fungal debris in the oropharyngeal region and supraglottic edema in any of our patients. The intubation difficulty score was calculated with the help of the intubation difficulty scale. Eleven patients had no intubation difficulty, 42 patients had slight intubation difficulty (score 1-4), 3 patients had moderate to major intubation difficulty (score $>5$ ).

We had a dedicated COVID-19 operation theatre with all the healthcare staff wearing level 3 personal protective equipment.[20] We checked all equipment and drugs for anticipated or unanticipated difficult airway management. We had masks of different sizes, stylets, bougies, laryngeal mask airways of different sizes, video laryngoscope (C-MAC) blades of different sizes, fiberoptic bronchoscope, 2 working suction apparatus, and an emergency tracheostomy trolley for management of the unexpected difficult airway.

COVID-19 is a major contributor to morbidity and mortality due to dyspnea, poor functional status, chest pain or tightness, hypercoagulability, endocrine abnormalities especially impaired glycemic control, etc. This, in addition to mucormycosis, makes the prognosis worse in these patients.[21] In our study $42(73.7 \%)$ patients had a history of diabetes which was managed by administration of insulin perioperatively. Central venous catheters may be required peri-operatively for blood or blood product transfusions, for fluid replacement, inotropic or vasopressor support, and long-term infusion of amphotericin B.[22] We used Groshong® PICC catheter ( 4 and 5 Fr) in 47 patients and internal jugular venous cannulation in 7 patients. The use of systemic amphotericin B in the management of mucormycosis associated with COVID-19 has its distinct toxicities, the most important being nephrotoxicity. There are other side effects of amphotericin B such as hypokalaemia, hypomagnesemia, fever, dyspnoea, shivering, and hypotension.[23] In our study, 14 patients had pre-operative amphotericin B-induced nephrotoxicity.

The primary objective of surgical management is to debride all necrotic tissues. Our patients received both antifungal treatment and surgical treatment. The overall mortality rate of mucormycosis is $54 \%$.[11] The mortality rate of mucormycosis associated with COVID-19 is still unknown. In our study, mortality occurred in 7 (12.3\%) patients. The median mortality 
time was 60 (range, 27-74) days. The median (range) mortality time was 60 (27-74) days. The median (range) time to hospital discharge was 53.5 (10-85) days. Five (12.2\%) of 41 patients with sinonasal mucormycosis and $2(14.3 \%)$ of 14 patients with rhino orbital mucormycosis (cerebral extension in 1 patient) expired. None of the patients with palatal mucormycosis expired.

Our study has some limitations. First, the study had a retrospective nature and was based on analysis of anesthesia and hospital records that may be subject to selection bias. Second, all the patients were from a single center. The number of expired patients was comparatively small (7 patients) for statistical comparison with those who were discharged (50 patients).

\section{Conclusion}

In patients undergoing surgery for mucormycosis associated with the coronavirus disease, airway management was easy to slightly difficult in most patients. Perioperative complications related to airways, the effect of COVID-19 and diabetes mellitus, systemic effects of amphotericin B can be reduced by taking timely and precautionary measures.

\section{References}

[1] Patel A, Kaur H, Xess I, Michael JS, Savio J, Rudramurthy S, et al. A multicentre observational study on the epidemiology, risk factors, management and outcomes of mucormycosis in India. Clin Microbiol Infect 2020;26:944.e9-944.e15. https://doi.org/10.1016/j.cmi.2019.11.021.

[2] Prakash H, Chakrabarti A. Global Epidemiology of Mucormycosis. J Fungi 2019;5:26. https://doi.org/10.3390/jof5010026.

[3] Black fungus: India reports nearly 9,000 cases of rare infection. BBC News 2021.

[4] Elavarasi A, Sagiraju HKR, Garg RK, Ratre B, Sirohiya P, Gupta N, et al. Clinical features, demography and predictors of outcomes of SARS-CoV-2 infection in a tertiary care hospital in India-A cohort study. Infectious Diseases (except HIV/AIDS); 2021. https://doi.org/10.1101/2021.08.10.21261855.

[5] Malhotra HS, Gupta P, Mehrotra D, Dandu H, Kohli N, Verma V, et al. COVID-19 associated mucormycosis: Staging and management recommendations (Report of a multi-disciplinary expert committee). J Oral Biol Craniofacial Res 2021;11:569-80. https://doi.org/10.1016/j.jobcr.2021.08.001.

[6] Skiada A, Pavleas I, Drogari-Apiranthitou M. Epidemiology and Diagnosis of Mucormycosis: An Update. J Fungi 2020;6:265. https://doi.org/10.3390/jof6040265.

[7] Anesthetic management of rhinoorbitocerebral mucormycosis; Focus on challenges PubMed n.d. https://pubmed.ncbi.nlm.nih.gov/31399350/ (accessed July 21, 2021).

[8] Eckmann DM, Seligman I, Cote CJ, Hussong JW. Mucormycosis Supraglottitis on Induction of Anesthesia in an Immunocompromised Host: Anesth Analg 1998;86:72930. https://doi.org/10.1097/00000539-199804000-00010.

[9] Malhotra N, Bajwa SS, Joshi M, Mehdiratta L, Kurdi M. Second wave of COVID-19 pandemic and the surge of mucormycosis: Lessons learnt and future preparedness: 
Indian Society of Anaesthesiologists (ISA National) Advisory and Position Statement. Indian J Anaesth 2021;65:427. https://doi.org/10.4103/ija.ija_520_21.

[10] Laniado-Laborín R, Cabrales-Vargas MN. Amphotericin B: side effects and toxicity. Rev Iberoam Micol 2009;26:223-7. https://doi.org/10.1016/j.riam.2009.06.003.

[11] Mucormycosis Statistics | Mucormycosis | Fungal Diseases | CDC 2020. https://www.cdc.gov/fungal/diseases/mucormycosis/statistics.html (accessed July 21, 2021).

[12] Fan J, Jiang Y, Hu K, Chen X, Xu Q, Qi Y, et al. Barriers to using personal protective equipment by healthcare staff during the COVID-19 outbreak in China. Medicine (Baltimore) 2020;99:e23310. https://doi.org/10.1097/MD.0000000000023310.

[13] El-Ganzouri AR, McCarthy RJ, Tuman KJ, Tanck EN, Ivankovich AD. Preoperative Airway Assessment: Predictive Value of a Multivariate Risk Index. Anesth Analg 1996;82:1197-204.

[14] Mouri Mi, Krishnan S, Maani CV. Airway Assessment. StatPearls, Treasure Island (FL): StatPearls Publishing; 2021.

[15] Adnet F, Borron SW, Racine SX, Clemessy J-L, Fournier J-L, Plaisance P, et al. The Intubation Difficulty Scale (IDS). Anesthesiology 1997;87:1290-7. https://doi.org/10.1097/00000542-199712000-00005.

[16] Angadi SP, Frerk C. Videolaryngoscopy and Cormack and Lehane grading. Anaesthesia 2011;66:628-9. https://doi.org/10.1111/j.1365-2044.2011.06777.x.

[17] O’Loughlin EJ, Swann AD, English JD, Ramadas R. Accuracy, intra- and inter-rater reliability of three scoring systems for the glottic view at videolaryngoscopy. Anaesthesia 2017;72:835-9. https://doi.org/10.1111/anae.13837.

[18] Doyle DJ, Goyal A, Bansal P, Garmon EH. American Society of Anesthesiologists Classification. StatPearls, Treasure Island (FL): StatPearls Publishing; 2021.

[19] Karaaslan E. Anesthetic management of rhinoorbitocerebral mucormycosis; Focus on challenges. J Mycol Medicale 2019;29:219-22. https://doi.org/10.1016/j.mycmed.2019.07.001.

[20] 2019-02-11-aide-memoire-for-levels-of-personal-protective-equipment-ppe-forhealthcare-workers-for-patient-care.pdf n.d.

[21] Mehta S, Pandey A. Rhino-Orbital Mucormycosis Associated With COVID-19. Cureus n.d.;12:e10726. https://doi.org/10.7759/cureus.10726.

[22] Scoppettuolo G, Biasucci DG, Pittiruti M. Vascular access in COVID-19 patients: Smart decisions for maximal safety. J Vasc Access 2020;21:408-10. https://doi.org/10.1177/1129729820923935.

[23] Kulkarni PK, Reddy NB, Shrinivas B, Takkalki VV. Anesthetic considerations in the management of mucormycosis 2015. https://doi.org/10.4103/2230-8598.165986. 
medRxiv preprint doi: https://doi.org/10.1101/2021.09.06.21263168; this version posted November 1, 2021. The copyright holder for this preprint (which was not certified by peer review) is the author/funder, who has granted medRxiv a license to display the preprint in perpetuity.

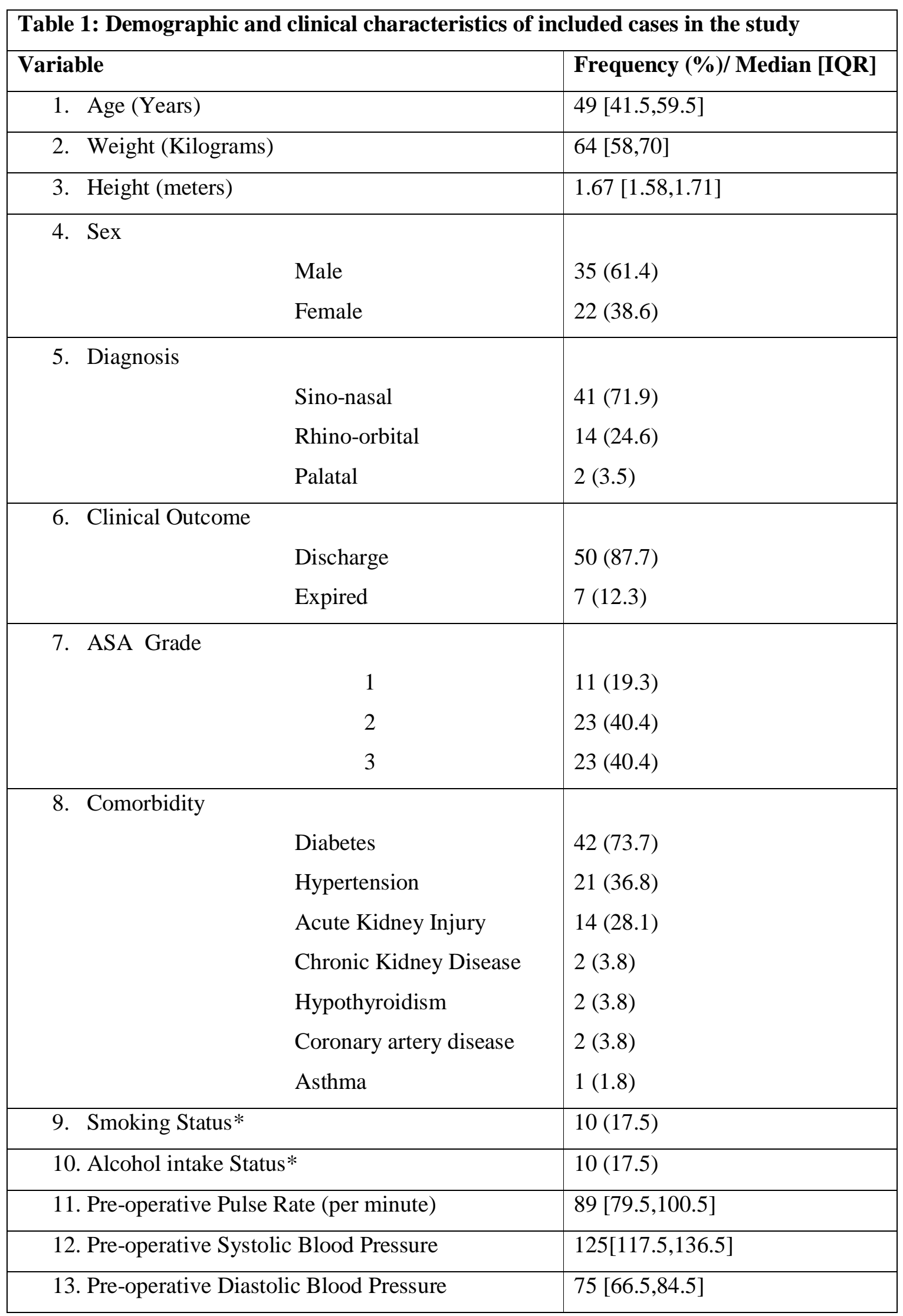


medRxiv preprint doi: https://doi.org/10.1101/2021.09.06.21263168; this version posted November 1, 2021. The copyright holder for this preprint (which was not certified by peer review) is the author/funder, who has granted medRxiv a license to display the preprint in perpetuity.

All rights reserved. No reuse allowed without permission.

\begin{tabular}{|lll|l|}
\hline $\begin{array}{c}\text { 14. Pre-operative } \\
\text { minute) }\end{array}$ & Respiratory rate (breaths per & \\
\hline
\end{tabular}

* Items are mutually non-exclusive 


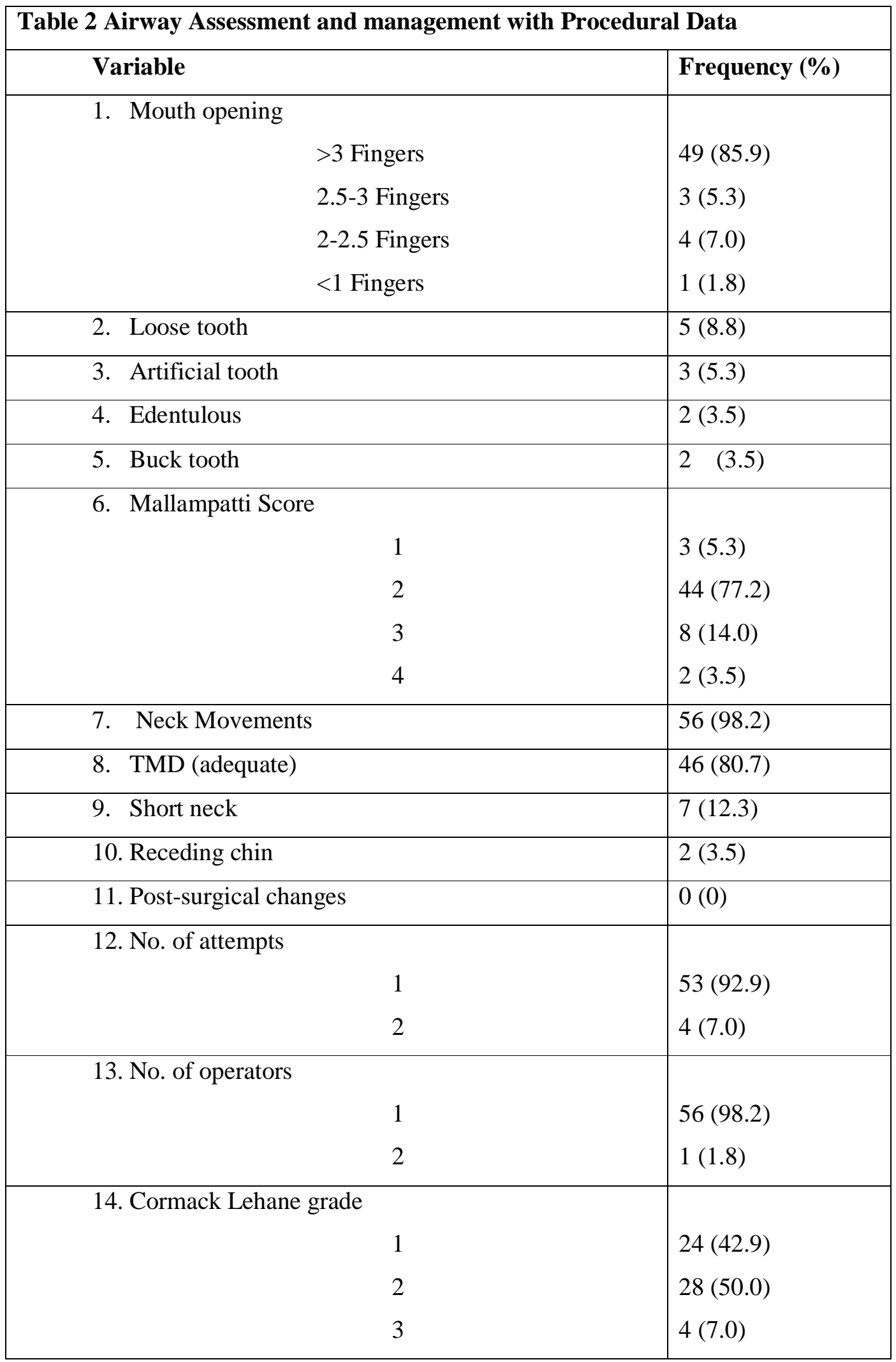


medRxiv preprint doi: https://doi.org/10.1101/2021.09.06.21263168; this version posted November 1, 2021. The copyright holder for this preprint (which was not certified by peer review) is the author/funder, who has granted medRxiv a license to display the preprint in perpetuity.

All rights reserved. No reuse allowed without permission.

\begin{tabular}{|c|c|}
\hline \multicolumn{2}{|l|}{ 15. Lifting force required } \\
\hline Normal & $24(42.9)$ \\
\hline Increased & $32(57.1)$ \\
\hline \multicolumn{2}{|l|}{ 16. Vocal cord mobility } \\
\hline Abduction & $57(100)$ \\
\hline 17. External laryngeal maneuver & $21(36.8)$ \\
\hline 18. Esophageal intubation & $0(0)$ \\
\hline 19. Intubation Stylet used & $2(3.6)$ \\
\hline \multicolumn{2}{|l|}{ 20. Intubation difficulty score $(\mathrm{n}=56)$} \\
\hline 0 & $11(19.6)$ \\
\hline 1 & $13(23.2)$ \\
\hline 2 & $17(30.4)$ \\
\hline 3 & $11(19.6)$ \\
\hline 4 & $1(1.8)$ \\
\hline 5 & $3(5.4)$ \\
\hline 21. Extubated & $41(71.9)$ \\
\hline 22. Shifted to ICU (Intubated) & $16(28.1)$ \\
\hline
\end{tabular}




\begin{tabular}{|c|c|}
\hline Variable & Median [IQR] \\
\hline 1. Pre-Op Blood sugar (mg/dL) & $146[122.5,171]$ \\
\hline 2. D-dimer $(\mathrm{ng} / \mathrm{mL})$ & $407[227,657.75]$ \\
\hline 3. Fibrinogen $(\mathrm{mg} / \mathrm{dL})$ & $484[415.75,556]$ \\
\hline 4. Prothrombin Time (sec) & $11.8[10.97,12.97]$ \\
\hline 5. INR & $1[0.93,1.14]$ \\
\hline 6. Hemoglobin $(\mathrm{g} / \mathrm{dL})$ & $11.35[10.32,12.7]$ \\
\hline 7. WBC Count $(/ \mu \mathrm{L})$ & $8.84[7,11.94]$ \\
\hline 8. Platelet Count $(/ \mu \mathrm{L})$ & $235.5[181.25,303.75]$ \\
\hline 9. Neutrophils (\%) & $77.3[69.5,85.05]$ \\
\hline 10. Ferritin $(\mathrm{ng} / \mathrm{mL})$ & $862.85[495.62,1381.57]$ \\
\hline 11. Lactate dehydrogenase (units/L) & $295[225,349]$ \\
\hline 12. C-reactive protein $(\mathrm{mg} / \mathrm{L})$ & $11.22[5.02,14.99]$ \\
\hline 13. Procalcitonin (ng/mL) & $0.09[0.04,1.17]$ \\
\hline 14. Interleukin-6 (pg/mL) & $17.5[8.7,43]$ \\
\hline 15. Total Bilirubin(mg/dL) & $0.43[0.3,0.58]$ \\
\hline 16. Direct Bilirubin(mg/dL) & $0.18[0.1,0.26]$ \\
\hline 17. Alanine aminotransferase (U/L) & $29[17,45]$ \\
\hline 18. Aspartate Aminotransferase (U/L) & $24[20.5,35]$ \\
\hline 19. Total Protein $(\mathrm{g} / \mathrm{dL})$ & $5.9[5.31,6.4]$ \\
\hline 20. Albumin (g/dL) & $3.2[2.8,3.6]$ \\
\hline 21. Albumin/Globulin Ratio & $1.27[1.07,1.43]$ \\
\hline 22. Alkaline Phosphatase (IU/L) & $98[87,138.5]$ \\
\hline 23. Urea $(\mathrm{mg} / \mathrm{dL})$ & $34.2[21.2,48.15]$ \\
\hline 24. Creatinine $(\mathrm{mg} / \mathrm{dL})$ & $0.87[0.69,1.7]$ \\
\hline 25. Calcium (mg/dL) & $8.11[7.87,8.64]$ \\
\hline 26. Sodium (mmol/L) & $136[134,139]$ \\
\hline 27. Potassium (mmol/L) & $4[3.55,4.7]$ \\
\hline 28. Uric Acid (mg/dL) & $4.3[3.3,5.1]$ \\
\hline
\end{tabular}

